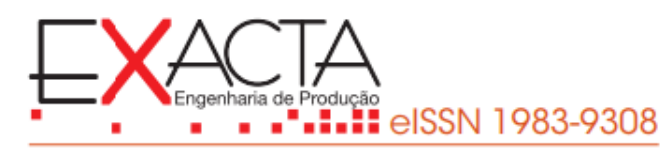

\title{
GERENCIAMENTO DE PORTFÓLIO DE PROJETOS EM ASSOCIAÇÃO SEM FINS LUCRATIVOS: UMA ABORDAGEM UTILIZANDO O MÉTODO MACBETH
}

\section{MANAGEMENT OF PROJECT PORTFOLIO IN PROFESSIONAL ASSOCIATION: AN APPROACH USING THE MACBETH METHOD}

Recebido em: 13 jun. 2019

Aprovado em: 13 fev. 2020

Versão do autor aceita publicada online: 13 fev. 2020

Publicado online: 18 maio 2021

Como citar esse artigo - American Psychological Association (APA):

Botelho, J. C., Silva, P. G. M., \& Bello, L. A. L. (2021, jul./set.). Gerenciamento de portfólio de projetos em associação sem fins lucrativos: uma abordagem utilizando o Método MACBETH. Exacta, 19(3), 587-608. https://doi.org/10.5585/exactaep.2021.14234.

Submeta seu artigo para este periódico $\bigoplus$

Dados Crossmark 


\title{
GERENCIAMENTO DE PORTFÓLIO DE PROJETOS EM ASSOCIAÇÃO SEM FINS LUCRATIVOS: UMA ABORDAGEM UTILIZANDO O MÉTODO MACBETH
}

\author{
MANAGEMENT OF PROJECT PORTFOLIO IN PROFESSIONAL ASSOCIATION: AN APPROACH \\ USING THE MACBETH METHOD
}

iD Janine Campos Botelho ${ }^{1}$

iD Peri Guilherme Monteiro da Silva²

iD Leonardo Augusto Lobato Bello ${ }^{3}$
Resumo: A economia globalizada gera um alto grau de competitividade entre as organizações, que se utiliza de técnicas de gerenciamento para melhorar constantemente seus processos e serviços. Sob este complexo cenário no mundo dos negócios, a implementação da gestão de portfólio otimiza a alocação de recursos e reduz perdas nas atividades realizadas dentro das instituições. Este trabalho teve como finalidade a aplicação do método multicritério MACBETH para facilitar o processo de tomada de decisão, buscando a priorização de projetos que serão propostos para a criação de um portfólio de projetos em instituição do terceiro setor no município de Marabá. A pesquisa foi realizada com auxílio da gestora de projetos da instituição, que foi de total importância para o sucesso de este trabalho ser alcançado. Pretendeu-se avaliar o processo de seleção e priorização de projetos, para que a entidade consiga maximizar seus recursos e se tornar sustentável no mercado. Obtendo como resultado a hierarquização dos dez projetos analisados, e tendo o projeto Saúde Bucal como o principal do portfólio da instituição.

Palavras-chave: Terceiro setor. Método Macbeth. Portfólio.

Abstract: The globalized economy generates a high degree of competitiveness among organizations, which use management techniques to constantly improve their processes and services. Under this complex scenario in the business world, the implementation of portfolio management optimizes the allocation of resources and reduces losses in the activities performed within the institutions. This work aimed to the application of the multicriteria MACBETH method to facilitate the decision-making process, seeking the prioritization of projects that will be proposed for the creation of a portfolio of projects in a third sector institution in the municipality of Marabá. The research was carried out with the help of the institution's project manager, which was of total importance for the success of this work to be achieved. It was intended to evaluate the process of selection and prioritization of projects, so that the entity can maximize its resources and become sustainable in the market. As a result, the hierarchization of the ten projects analyzed was carried out, and the Oral Health project was the main focus of the institution's portfolio.

Keywords: Third sector. Macbeth method. Portfolio. 


\section{Introdução}

A incerteza do mercado global presente no século XXI intensifica a concorrência entre as organizações trazendo novas exigências no processo de tomada de decisão. Para garantir vantagem competitiva e eficiência nas operações, as empresas buscam ferramentas de gestão que possam garantir melhores resultados. O gerenciamento de portfólio de projetos proporciona o alinhamento dos objetivos estratégicos da empresa, com as atividades e projetos a serem desenvolvidas, para que a otimização dos recursos seja alcançada.

No início da década de 1980 a recessão econômica e o endividamento externo do país geraram a discussão em torno do papel do Estado na economia e da crise fiscal, situação agravante do quadro de exclusão e desigualdade social. Como estratégia para enfrentar essas sequelas, oriundas da efetivação da proposta neoliberal, o governo brasileiro estabeleceu parcerias entre o Estado e a sociedade civil e um dos resultados foi o surgimento dos "três setores sociais" ou "esquema trinário": o primeiro setor, sendo composto pelo governo, seus recursos e fins públicos; o segundo setor, constando o ramo privado, constituindo-se de empresas do ramo privado, seus recursos e fins privados; e por último, o terceiro setor constituído pelas organizações da sociedade civil de iniciativa privada sem fins lucrativos, cada vez mais ativas na busca do atendimento das demandas sociais (Duarte, 2005; Albuquerque, 2006).

Todas as organizações, com ou sem fins lucrativos, necessitam de recursos para viabilizar sua atividade, de forma que se obtenha resultado positivo com a operação. Camargo (2001) ressalta que muitas das organizações do terceiro setor têm como principal dificuldade encontrada, a escassez de recursos, seguida, do baixo investimento do governo.

As organizações do Terceiro setor para garantir eficácia em suas operações, buscam estabelecer parcerias, mobilizar recursos e atender as demandas dos stakeholders envolvidos. Instituições sem fins lucrativos necessitaram organizar a realização da gestão de seus projetos, sendo esta mais uma composição de suas ações administrativas, tendo como meta realizar e garantir sua sustentabilidade (Melo Neto \& Brennand, 2004).

Este artigo objetivou-se em determinar a hierarquia de priorização entre projetos de uma entidade do terceiro setor, situada na cidade de Marabá no estado do Pará, já que a instituição estudada não tem controle organizacional entre seus projetos e verifica-se que isto é considerável para realizar a gestão de investimento de seus recursos adquiridos. Esta instituição tem como missão a inclusão de crianças e jovens com deficiência a sociedade. Os critérios utilizados no estudo foram baseados em entrevista com responsável pela gestão, estes foram alocados no método Macbeth. A gestão de organizações do terceiro setor aflora como tema de suma importância, pois torna-se necessário realizar compreensão como os processos de gestão influenciam na atuação destas instituições na comunidade em que estão inseridas (Assumpção \& Campos, 2011). 


\section{Necessidade da gestão de projetos no Terceiro Setor}

O processo de tomada de decisão em organizações envolve fases até chegar à efetiva tomada de decisão, de acordo com os objetivos da organização, sejam eles implícitos ou explícitos. Para cada situação o decisor pode ou não levar em conta as etapas do processo decisório, pelo fato de elas estarem intimamente relacionadas ao tipo de problema ou oportunidade e o nível de conhecimento que o decisor tem das circunstâncias internas e externas envolvidas no processo de decisão (Andrade \& Amboni, 2010).

A gestão no terceiro setor é considerada controversa e complexa, isto ocorre como consequência de o indivíduo a frente da organização pensar em promover benefício social, porém sem ter conhecimento de práticas administrativas ou se tem não sabe como aplicá-las (McCarthy, 2008).

Deve-se entender a necessidade do terceiro setor à sociedade como uma forma de tentativa de solucionar problemas sociais ou de realizar tentativas de integração de pessoas ao convívio social, tendo a possibilidade de criação do empreendedorismo social, tendo em vista que formula a missão de criação de valor social através de inovação e organização socioeconômica, utilizando os recursos financeiros para garantir a sustentabilidade à sociedade (Hervieux, Gedajlovic, \& Turcotte, 2010).

Salvatore (2004) expõe a necessidade de que qualquer instituição filantrópica deva compreender a necessidade de adotar mecanismos e técnicas de gestão do mundo empresarial privado, desta forma criar nos gestores o mito de atitudes empresariais sendo boas ou o que é bom para empresas privadas torna-se bom para o terceiro setor e desta forma alcançar sobrevivência no mercado globalizado.

No terceiro Setor os projetos são muitas vezes responsáveis pela manutenção de instituições. É, portanto, de extrema importância à elaboração de um projeto exclusivamente para custeio de despesas principais, tais como luz, água, telefone e folha de pagamento de colaboradores indiretos (Xavier \& Chueri, 2008; Nemoto, Silva, \& Pinochet, 2018).

A dinâmica da captação de recursos no Brasil consiste na elaboração de projetos para financiar e promover campanhas, tendo como objetivo alcançar contribuição financeira junto a civis, estado e organizações internacionais e instituições privadas (Franco, 2003; Lima, Fernandes, \& Qualharini, 2017).

\section{Método Macbeth (Measuring Attractivness by a Category Based Evaluation Technique)}

Os métodos multicritério são modelos de apresentação formal e simplificada da realidade, estes representam um sistema ou uma situação real e permitem a sua análise para que conclusões possam ser tiradas sobre seu funcionamento e desempenho (Almeida, 2013; Segalla, Zattar, Lima, \& Seleme, 2019).

Um método de apoio à decisão consiste numa formulação metodológica ou numa teoria, com 
estrutura axiomática bem definida, que pode ser usado para construir um modelo de decisão que vise à solução de um problema de decisão específico. Os métodos têm uma característica mais genérica e se aplica a uma classe mais ampla de problemas de decisão, enquanto o modelo de decisão tem uma natureza especifica, devendo muitas vezes incorporar a estrutura de preferencias de um decisor (Almeida, 2013; Sousa, Jerônimo, Melo, \& Aquino, 2017).

Salomon (2004) informa o método MACBETH - Measuring Attractivness by a Categoy Based Evaluation Technique, sendo metodologia que agrega conceitos da escola americana e francesa no qual, modelos de problemas de programação linear são utilizados para descrever o grau de preferência das alternativas. Este método requer apenas julgamentos de natureza qualitativa sobre diferenças de atratividade, com uma escala de seis níveis entre opções e permite a construção de uma escala numérica (Bana e Costa, De Corte, \& Vansnick, 2012).

Esta técnica permite realizar análises de diversas opções, realizando comparação quantitativa de componentes em termos de suas diferenças de atratividade em múltiplos critérios (Almeida \& Neto, 2015). MACBETH foi criado no início da década de 1990 pelos professores doutores Costa e Vasnick, esta equipe foi ampliada em anos conseguintes com a chegada do também professor doutor De Corte (Carayannins et al., 2018). Este método tem como diferencial em relação a outras metodologias de tomada de decisão, a ponderação de critérios e a opinião sobre as opções em julgamentos qualitativos sobre diferenças de atratividade (Bana e Costa, De Corte, \& Vansnick, 2016). Goes (2017) corrobora informando que em MACBETH as comparações entre os critérios não são realizadas em pares, como no procedimento do Analytic Hierarchy Procces, mas ocorre a aferição utilizando normas padronizadas que são estabelecidas conforme os critérios a serem utilizados.

Os valores de cada opção são extraídos dos valores do decisor ou decisores, para o método ser colocado em prática e o problema ser solucionado. Este método possui quatro fases ou etapas principais: Estruturação dos elementos de avaliação, desenvolvimento do modelo multicritério de avaliação, análise de sensibilidade e elaboração de recomendações e análise do contexto de decisão e estruturação do processo de apoio à decisão (Bana e Costa et al. 2012).

Bana e Costa et al. (2012) explicam que o decisor deve dizer se entre duas alternativas qual se torna a mais atrativa com relação a critério específico e qual o grau de atratividade em uma escala semântica (muito fraca, fraca, moderada, forte, muito forte e extrema). A matriz de julgamentos deve apresentar consistência, sendo que: opções igualmente atrativas obtenham mesma pontuação, quando uma opção for mais atrativa deve obter pontuação maior e para atingir a condição de existência cardinal, avalia-se a diferença entre atratividade de duas opções (muito forte, por exemplo) é maior ou menor da diferença atrativa entre outras duas opções (moderada, como exemplo).

A escala MACBETH, como é chamada, é normalizada fornecendo pesos para as alternativas em avaliação o que possibilita o uso de um modelo aditivo. A terceira fase de aplicação do método consiste 
na avaliação do modelo multicritério, levando em conta a estruturação de uma função sobre cada descritor de impacto, e a ponderação da escala gerada (Lima, 2012).

E por fim, é realizada a análise de sensibilidade e recomendações, onde de acordo com os autores Bana e Costa et al. (2016), o decisor pode visualizar como uma mudança qualquer dos pesos afetaria o resultado gerado.

\section{Caracterização do problema em análise}

Atualmente a instituição do terceiro setor presta serviços especializados na área educacional a mais de 500 pessoas com deficiência intelectual e múltipla do município em questão, e provenientes de outros municípios em um raio de $110 \mathrm{~km}$. A associação oferece aos alunos/usuários atendimentos de fisioterapia, fonoaudiologia, terapia ocupacional, odontologia, psicologia, assistência social, nutrição, psicomotricidade e educação especializada.

Para prestar tais serviços e promover atividades, a entidade busca a elaboração e desenvolvimento de projetos, parcerias com organizações privadas e órgãos governamentais, objetivando sanar sua deficiência de recursos financeiros. Dessa forma, gerencia uma gama de projetos, que compõe o seu portfólio atual, apesar de não utilizar nenhuma técnica de gerenciamento que facilite o planejamento.

Portanto é de fundamental importância que a instituição verifique e reconheça quais os projetos são mais atrativos, mesmo com a limitação de recursos, a mesma possa ser eficiente nos processos, buscando aperfeiçoar os procedimentos de controle dos insumos otimizando-os e alinhando o portfólio a seus objetivos estratégicos.

\section{Metodologia e análise dos dados}

Para o desenvolvimento desta pesquisa, inicialmente, foram elencados os dez projetos que compõe o portfólio no ano de 2017, e eles são listados a seguir, informa-se que são expostas as suas nomenclaturas abreviadas entre parêntese, pois é desta forma que são identificados no software MMacbeth

- Projeto 1 - Reabilitação e Cultura para crianças e adolescentes com deficiência intelectual e múltipla (CMDCA): Desenvolver atividades especializadas com exercícios físicos, culturais e recreativos para crianças e adolescentes com deficiência intelectual e múltipla, contribuindo no seu processo de reabilitação, interação social e melhoria da qualidade de vida;

- Projeto 2 - Superação (SUPERAÇÃO): Proporcionar atenção integral e integrada à saúde para crianças e adolescentes com deficiência intelectual e múltipla desde a prevenção e até 
oportunizar para uma inclusão com responsabilidade e segurança possibilitando a superação do indivíduo em suas condições motoras, afetivas e sociais;

- Projeto 3 - Instituição em movimento (MOVIM.): Garantir o transporte adaptado e o melhoramento da estrutura física da instituição, para acessibilidade aos atendimentos especializados das crianças, jovens e adultos com deficiência intelectual, múltiplas e autismo;

- Projeto 4 - Saúde Bucal ao alcance de todos (SAÚDE B.): Proporcionar atenção integral e integrada a saúde para crianças e adolescentes e adultos com deficiência intelectual e múltipla e autismo, desde a prevenção e o tratamento específico de cada usuário. Oportunizando assim, qualidade de vida;

- Projeto 5 - Transportando Vidas (TRANSP. VIDAS): Buscar recursos a fim de viabilizar a compra de veículos para poder atender de forma mais humanizada, com conforto e segurança aos usuários. O veículo solicitado atende principalmente as condições técnicas de espaço interno, que possibilitam a circulação das mães com os usuários em cadeiras de rodas;

- Projeto 6 - Viver com Esporte (VIVER COM ESP.): Garantir o melhoramento com acessibilidade da estrutura física da quadra poliesportiva da instituição para o desenvolvimento das atividades desportivas com as crianças, adolescentes, jovens e adultos com deficiência intelectual, múltiplas e autismo;

- Projeto 7 - Reabilita com qualidade (REAB.): Proporcionar para crianças e adolescentes com deficiência intelectual e múltipla. Melhoria da qualidade de vida através da habilitação/reabilitação que é indispensável para autonomia em todas as instancias sociais;

- Projeto 8 - Informática aplicada a educação especial (INFORM. APLICADA): Utilizar a informática (computador), como recursos pedagógicos no processo de ensino - aprendizagem dos alunos com deficiência intelectuais e múltiplas visando à criatividade, raciocínio lógico, coordenação motora e autonomia;

- Projeto 9 - Equipar é preciso (EQUIPAR): Renovar o nosso patrimônio e atender à solicitação dos colaboradores e alunos que sobrevivem com móveis e bens com vida útil vencida que dificulta a sua aprendizagem;

- Projeto 10 - Mais ao norte levando saúde as pessoas com deficiência (MAIS AO NORTE): Ampliar o número de atendimentos oferecidos hoje à sociedade.

A partir das informações listadas sobre os projetos e seus objetivos pode-se iniciar a segunda etapa do trabalho, o uso do software M-Macbeth. Inicialmente realizou-se a inserção de nós-critérios e nós não critérios, que foram propostos com base na literatura e opinião da responsável pelo setor de projetos na organização. Os projetos são caracterizados como alternativas no método.

Para cada nó critério foi designada uma base de comparação, diferentemente dos nós não 
critérios que não precisam de base. Para inserir cada nó-critério definido a partir do nó global (Hierarquização de projetos), utilizou-se a base de comparação "opções + 2 referencias", que permitiu designar uma referência superior e uma referência inferior para a ponderação dos critérios, como pode ser visto no exemplo do critério "Complexidade", na Figura 1.

\section{Figura 1}

\section{Nó critério Complexidade no programa M-Macbeth}

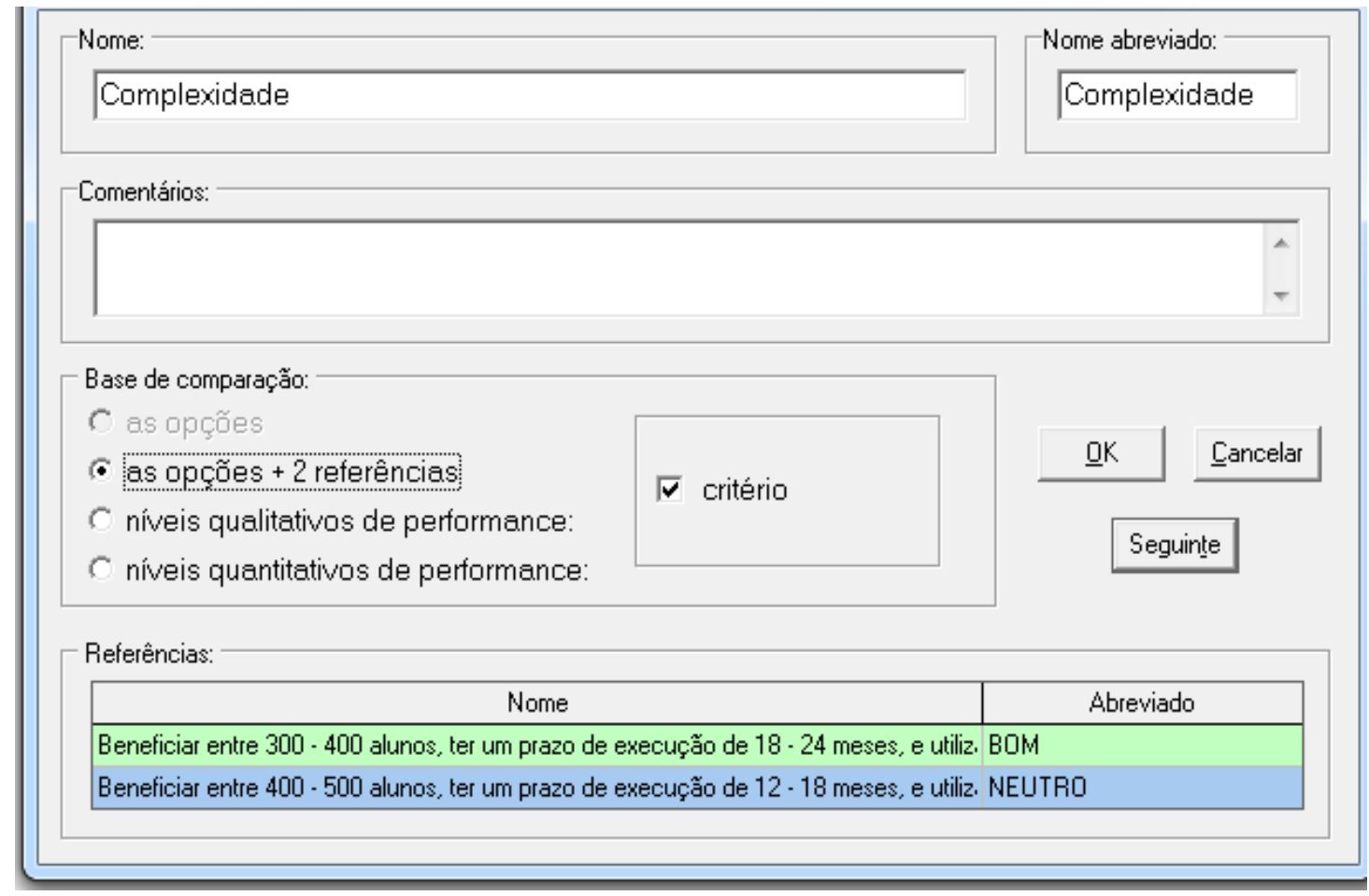

Fonte: Autores (2018).

As matrizes de julgamento de cada critério foram consistentes, estão disponíveis para visualização no Apêndice A, B e C, sendo A - Matriz de julgamento do critério "complexidade", B - Matriz de julgamento do critério "Alinhamento estratégico", C - Matriz de julgamento do critério "Dependência de terceiros". Com relação aos níveis de referências propostos para cada critério fundamental, os níveis de referência Neutro e Bom foram definidos e estão dispostos no Quadro 1. 


\section{Quadro 1}

Níveis de Referência dos Critérios Fundamentais

Critério

Alinhamento estratégico

Dependência de terceiros
Nível de referência inferior: NEUTRO

Beneficiar entre 300 a 400 alunos, ter um prazo de execução de 18 a

24 meses, e utilizar no mínimo $50 \%$ dos profissionais e equipamentos que já estão disponíveis.

Estar alinhado parcialmente com a missão, visão e objetivos estratégicos da instituição.

Apresentar total dependência de verbas governamentais, de doações empresariais ou de projetos de outras instituições.
Nível de referência superior: BOM

Beneficiar entre 400 a 500 alunos, ter um prazo de execução de 12 a 18 meses, e utilizar os profissionais e equipamentos que já estão disponíveis.

\section{Estar alinhado}

completamente com a missão, visão e objetivos estratégicos da instituição.

Apresentar parcial ou nenhuma dependência de verbas governamentais, de doações empresariais, ou de projetos de instituições.

Fonte: Autores (2018).

Os dados referentes a lista dos projetos que compõe o portfólio e Níveis de referência dos critérios fundamentais (Quadro 1) foram utilizados na criação da árvore de decisão onde um problema complexo é decomposto em sub-problemas mais simples e recursivamente esta técnica é aplicada a cada sub-problema, esta é apresentada pela Figura 2.

Figura 2

Árvore de decisão M-Macbeth

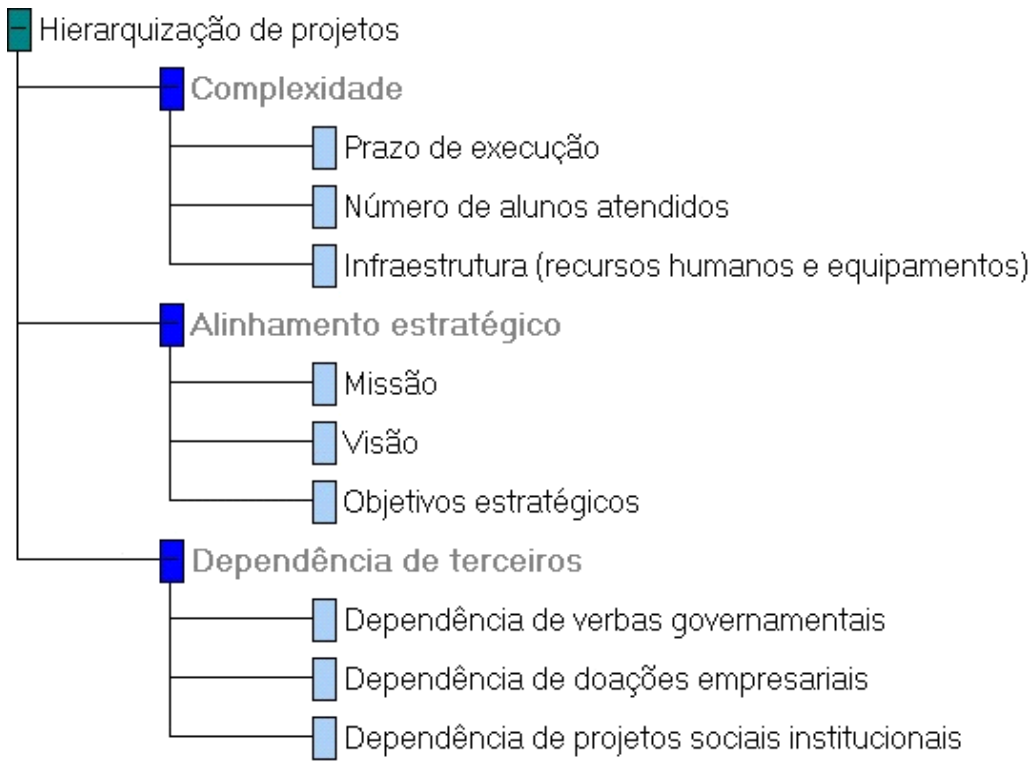

Fonte: Autores (2018). 
O Quadro 2 exibe a descrição dos nós critérios e nós não critérios utilizados durante a hierarquização dos projetos, a partir da atratividade de cada um. Foram utilizados então os critérios de complexidade, alinhamento estratégico e dependência de terceiros. Nota-se que o teste de independência de julgamentos dos decisores, tanto em relação à preferência ordinal como em relação à preferência cardinal, não foi necessário, visto que se utilizaram critérios que fossem variáveis presentes comuns em todos os projetos, para que o modelo pudesse ser coerente.

\section{Quadro 2}

Descrição de Nós Critérios e Nós Não-Critérios

\begin{tabular}{|c|c|c|}
\hline Nó-critérios & Nó não critérios & Descrição \\
\hline \multirow{3}{*}{ Complexidade } & Prazo de execução & $\begin{array}{c}\text { Prazo de execução das etapas do } \\
\text { projeto. }\end{array}$ \\
\hline & Número de alunos atendidos & $\begin{array}{c}\text { Número de alunos que serão } \\
\text { beneficiados pelo projeto em } \\
\text { questão. }\end{array}$ \\
\hline & Infraestrutura & $\begin{array}{c}\text { Profissionais e equipamentos } \\
\text { necessários para o } \\
\text { desenvolvimento do projeto. }\end{array}$ \\
\hline \multirow[t]{2}{*}{ Alinhamento estratégico } & Missão/visão & $\begin{array}{l}\text { Em que nível o projeto deve está } \\
\text { alinhado com a missão e visão da } \\
\text { instituição. }\end{array}$ \\
\hline & Objetivos estratégicos & $\begin{array}{c}\text { Em que nível o projeto está } \\
\text { alinhado com os objetivos } \\
\text { estratégicos. }\end{array}$ \\
\hline \multirow{3}{*}{ Dependência de terceiros } & $\begin{array}{l}\text { Dependência de verbas } \\
\text { governamentais }\end{array}$ & $\begin{array}{c}\text { Se o investimento do projeto } \\
\text { advém de programas } \\
\text { governamentais. }\end{array}$ \\
\hline & $\begin{array}{c}\text { Dependência de doações } \\
\text { empresariais }\end{array}$ & $\begin{array}{c}\text { Se o investimento do projeto } \\
\text { advém de doações de empresas } \\
\text { privadas. }\end{array}$ \\
\hline & $\begin{array}{l}\text { Dependência de projetos sociais } \\
\text { institucionais }\end{array}$ & $\begin{array}{c}\text { Se o projeto é desenvolvido sob } \\
\text { um edital publicado por outra } \\
\text { organização que financia projetos } \\
\text { sociais. }\end{array}$ \\
\hline
\end{tabular}

Fonte: Autores (2018).

Para gerar a escala Macbeth de pesos, foi pedido à gestora que escolhesse entre um conjunto de sete julgamentos (nula; muito fraca; fraca; moderada; forte; muito forte; e, extrema), para avaliar a diferença de atratividade entre as alternativas (projetos) selecionadas no estudo.

A matriz de julgamento de cada critério teve julgamento consistente e desta forma aponta-se que o processo no programa está correto. A Figura 3 exibe as escalas de julgamento do programa MMacbeth para os critérios de complexidade, alinhamento estratégico e dependência de terceiros. 
Figura 3

Escala de Julgamentos do Programa M-Macbeth Para Os Critérios
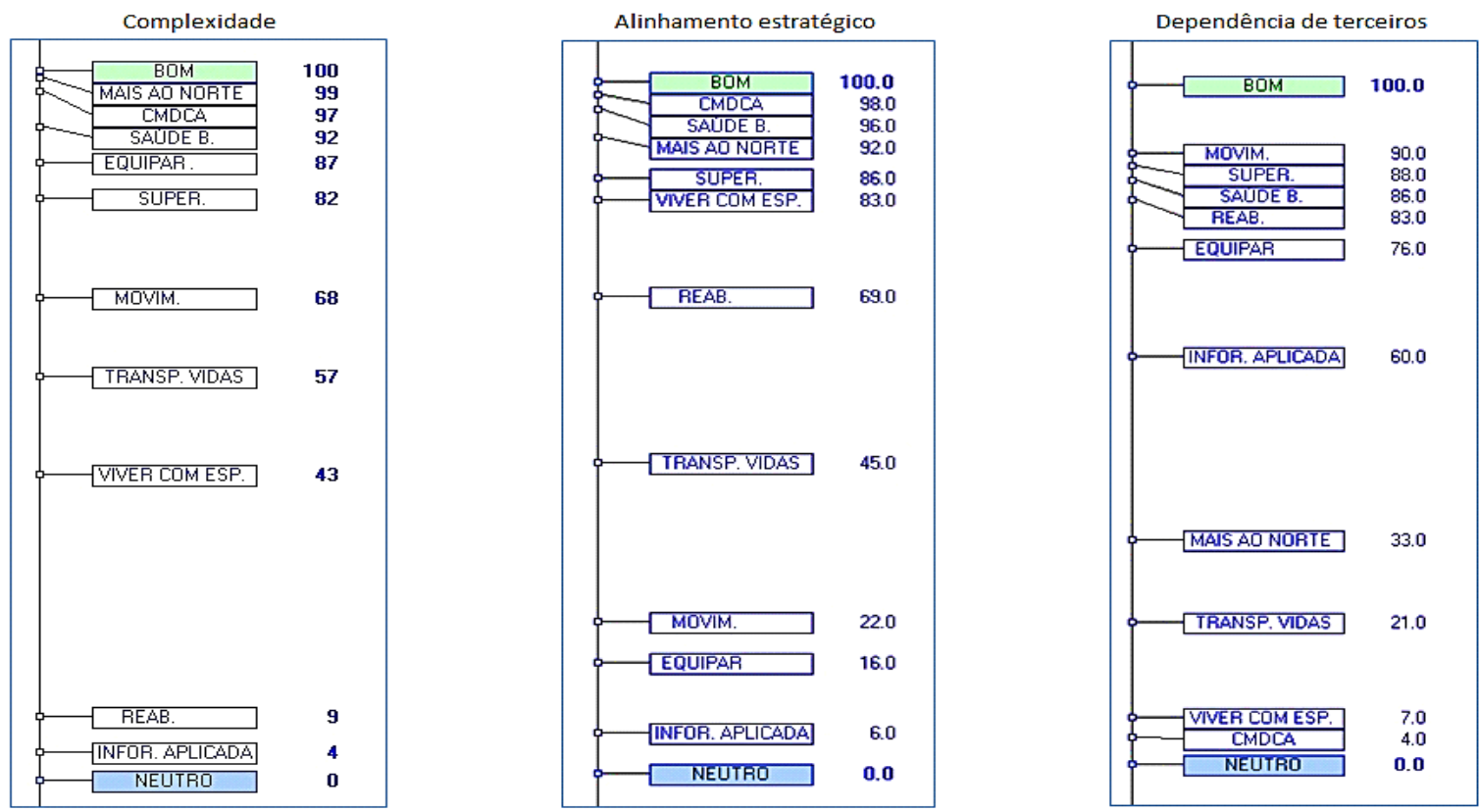

Fonte: Autores (2018).

De acordo com a escala gerada o projeto mais atrativo a partir do critério complexidade é o projeto 10 (MAIS AO NORTE) que apresenta um índice de 99 na escala, e o menos atrativo é o projeto 8 (INFORM. APLICADA) que apresenta um índice de apenas 4. No critério alinhamento estratégico, o projeto com o nível mais elevado, é o projeto 1 (CMDCA), que atinge um índice de 98 de atratividade com relação aos outros projetos, se distanciando extremamente do projeto 8 (INFOR. APLICADA), que apresenta o pior índice, no que diz respeito ao critério estudado, como apresentado na Figura 11 e por último em dependência de terceiros o projeto 3 (MOVIM.) mais fortemente do que os outros projetos estudados. Nota-se ainda que o projeto 1 (CMDCA) é o menos influenciado pelo critério fundamental estudado.

A terceira etapa do modelo de decisão Macbeth é realizar a ponderação dos critérios utilizados, a partir da matriz de julgamentos dos mesmos, que são realizados pela gestora da entidade utilizando ainda a mesma escala de julgamento que vai de "nula" até "extrema" para analisar a atratividade entre eles. O modo de ponderação utilizada neste trabalho foi o simples, visto que os pesos são atribuídos numa única etapa a todos os critérios simultaneamente, como pode ser visto na Figura 4. 
Figura 4

Ponderação dos Nós Critérios

\begin{tabular}{|c|c|c|c|c|c|}
\hline 㬂 & [ Complexidade ] & [Dependência ] & [Airinhamento ] & Neutro & extrema \\
\hline [Complexidade ] & nula & moderada & forte & mt. forte & mt. Forte \\
\hline [Dependência ] & & nula & moderada & forte & moderada \\
\hline [Alinhamento ] & & & nula & forte & \\
\hline Neutro & & & & nula & mt. fraca \\
\hline \multicolumn{5}{|c|}{ Julgamentos consistentes } & nula \\
\hline
\end{tabular}

Fonte: Autores (2018).

A partir da entrevista com a gestora, notou-se uma grande preocupação com a busca por um melhor gerenciamento de projetos dentro do portfólio que a instituição apresenta atualmente. Tal fato foi evidenciado na contribuição da mesma para os dados de execução das matrizes de julgamento, além das outras colaborações para o desenvolvimento do estudo.

A utilização do método MACBETH propôs uma forma de gerenciamento complexa que a entidade não conhecia e que ajudaria a instituição a definir melhor seu planejamento estratégico e seu processo de gestão de portfólio.

O resultado do termômetro global é gerado a partir de um modelo aditivo de agregação simples, logo, esse resultado é obtido através do somatório dos desempenhos de cada critério que são multiplicados pelos pesos que são encontrados na ponderação visualizada na Figura 4. Em forma crescente (SAÚDE B < SUPERAÇÃO < MAIS AO NORTE < EQUIPAR < MOVIM. $<$ CMDCA $<$ REAB. $<$ TRANSP. VIDAS < VIVER COM ESP. < INFORM. APLICADA), a partir da escala global visualizada na Figura 5, os projetos são hierarquizados de acordo com sua atratividade geral. 
Figura 5

Termômetro Global do Modelo

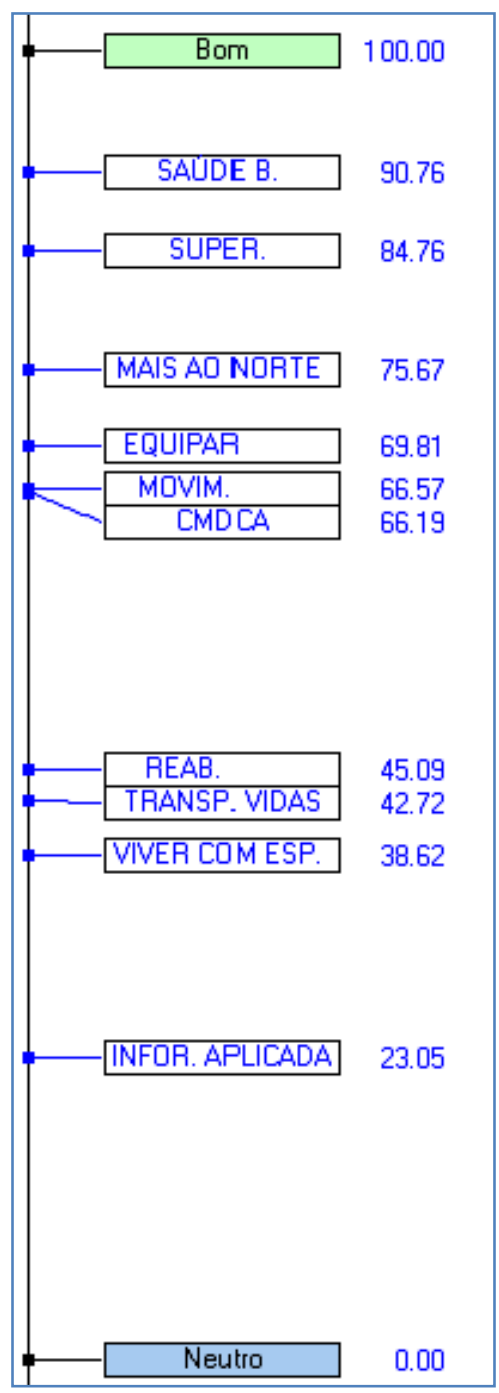

Fonte: Autores (2018).

De acordo com este modelo, o projeto que teve melhor desempenho levando-se em consideração todos os três critérios fundamentais e os seus respectivos coeficientes de ponderação, foi o projeto 4 (Saúde Bucal para todos) alcançando um índice de atratividade de 90,76, seguido do projeto 2 (Superação) com um índice de 84,76, que ficou acima do projeto 10 (Mais ao norte) que alcançou um índice de 75, 67. Com relação aos critérios definidos, o que pode ser observado na Figura 6 é que o mais relevante foi o critério "complexidade", seguido pelo critério "dependência de terceiros" e "alinhamento", respectivamente. 
Figura 6

Tabela de Pontuações e Resultado Global do Modelo

\begin{tabular}{|c|c|c|c|c|}
\hline Opçōes & Global & Complexidade & Alinhamento & Dependência \\
\hline CMDCA & 66.19 & 97.00 & 98.00 & 4.00 \\
\hline SUPER. & 84.76 & 82.00 & 86.00 & 88.00 \\
\hline MOVIM. & 66.57 & 68.00 & 22.00 & 90.00 \\
\hline SAÚDE B. & 90.76 & 92.00 & 96.00 & 86.00 \\
\hline TRANSP. VIDAS & 42.72 & 57.00 & 45.00 & 21.00 \\
\hline VIVER COM ESP. & 38.62 & 43.00 & 83.00 & 7.00 \\
\hline REAB. & 45.09 & 9.00 & 69.00 & 83.00 \\
\hline INFOA. APLICADA & 23.05 & 4.00 & 6.00 & 60.00 \\
\hline EQUIPAR APAE & 69.81 & 87.00 & 16.00 & 76.00 \\
\hline MAIS AO NORTE & 75.67 & 99.00 & 92.00 & 33.00 \\
\hline Bom & 100.00 & 100.00 & 100.00 & 100.00 \\
\hline Neutro & 0.00 & 0.00 & 0.00 & 0.00 \\
\hline \multicolumn{2}{|l|}{ Pesos: } & 0.4762 & 0.1905 & 0.3333 \\
\hline
\end{tabular}

Fonte: Autores (2018).

\section{Análise de sensibilidade}

A análise de sensibilidade no peso de um critério permite analisar em que medida as recomendações do modelo se alteram em hipótese o peso do critério for modificado, mantendo as relações de proporcionalidades entre os restantes dos pesos.

Neste estudo, primeiramente foram analisados os projetos que ficaram em primeiro e segundo lugar na escala global. Nota-se que os projetos (Saúde Bucal ao alcance de todos e Superação) com relação ao critério "complexidade", independente das variações no peso do critério, não teriam sua posição alterada na escala global, confirmando assim, que com relação a esse nó critério estudado, o projeto Saúde Bucal é sempre o mais atrativo, como visto na Figura 7.

Figura 7

Análise de Sensibilidade para o Critério "Complexidade" para os Projetos Saúde Bucal e Superação

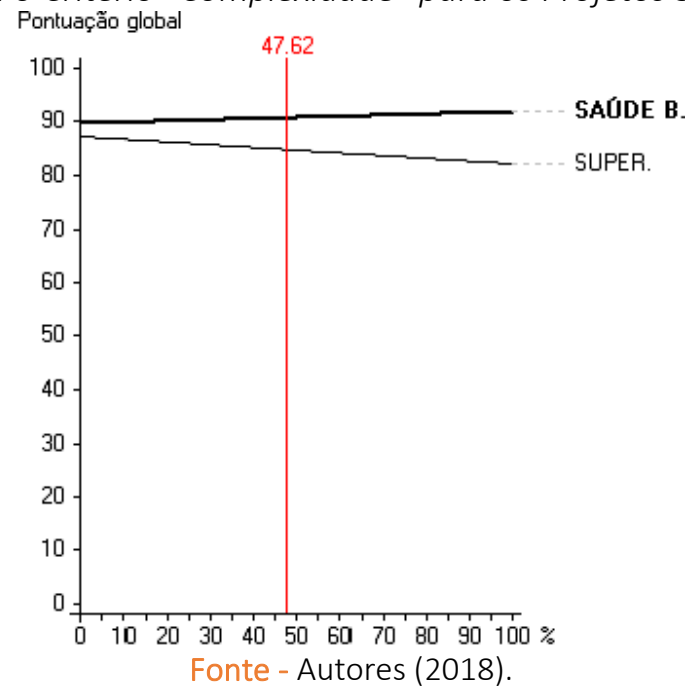


Nota-se que as linhas não se cruzam em consequência à diferença de peso no resultado global, que é de aproximadamente 10, que é gerada pelo fato de os dois projetos apresentarem grande discrepância no que diz respeito à complexidade. De acordo com a gestora, o projeto Saúde Bucal engloba $100 \%$ dos alunos da instituição, enquanto o projeto Superação atende apenas $40 \%$ dos estudantes, e tem um prazo de execução de 3 meses. O mesmo acontece quando se analisam os projetos (Saúde Bucal ao alcance de todos e Superação) com relação ao critério "alinhamento estratégico", percebe-se que o gráfico não apresenta alterações no seu posicionamento, o que pode ser visualizado na Figura 8.

Figura 8

Análise de Sensibilidade oara O Critério "Alinhamento Estratégico" para os Projetos Saúde Bucal e Superação

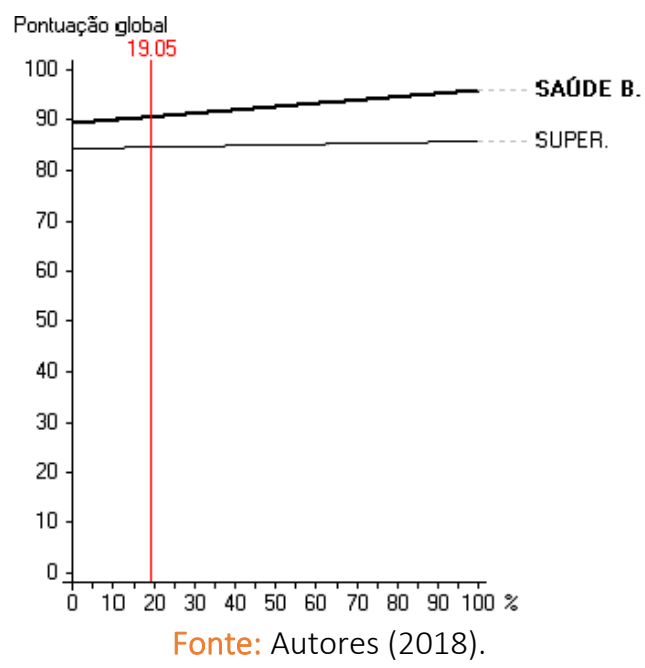

Na Figura 9, nota-se quando o peso do critério "dependência de terceiros" é superior a 83,3, o projeto Superação torna-se mais atrativo do que Saúde Bucal, situação causada pela diferença no resultado global entre os dois projetos ser pequena (de aproximadamente 4), mostrando que quando duas linhas de opções se interceptam, um projeto pode ser mais atrativo que outro de acordo com o critério verificado. 


\section{Figura 9}

Análise de Sensibilidade para o Critério "Dependência De Terceiros" para os Projetos Saúde Bucal e Superação

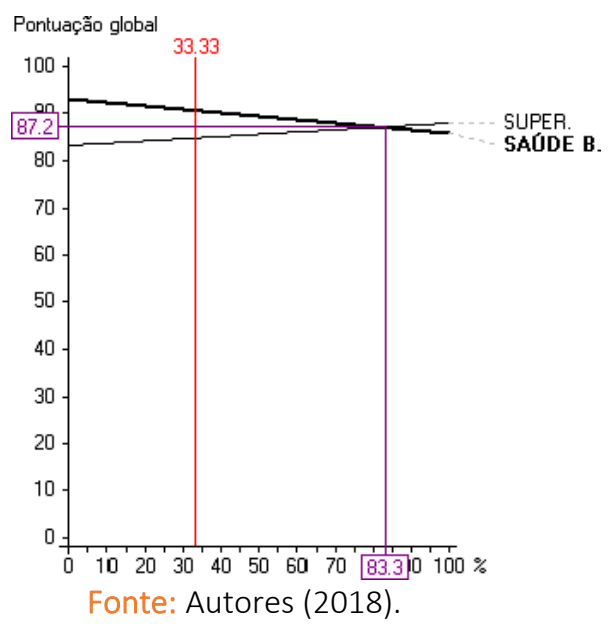

Quando se realiza a análise de sensibilidade com relação aos projetos que ficaram em primeiro e terceiro lugar (Saúde Bucal e Mais ao norte), respectivamente, nota- se que com relação ao critério "complexidade", quando seu peso aumenta para 83,4, a alternativa Mais ao norte passaria a ser a opção mais atrativa, o que pode ser notado na Figura 10. Tal alteração se dá pelo fato da diferença de peso entre os mesmos ser de 7 pontos no resultado global, a disparidade ocorre pelo fato do projeto Mais ao norte apresentar grande necessidade de corpo técnico para seu desenvolvimento, tendo assim um nível de complexidade similar ao do projeto Saúde bucal.

\section{Figura 10}

Análise de Sensibilidade do Critério "complexidade" para os Projetos Saúde Bucal e Mais ao Norte

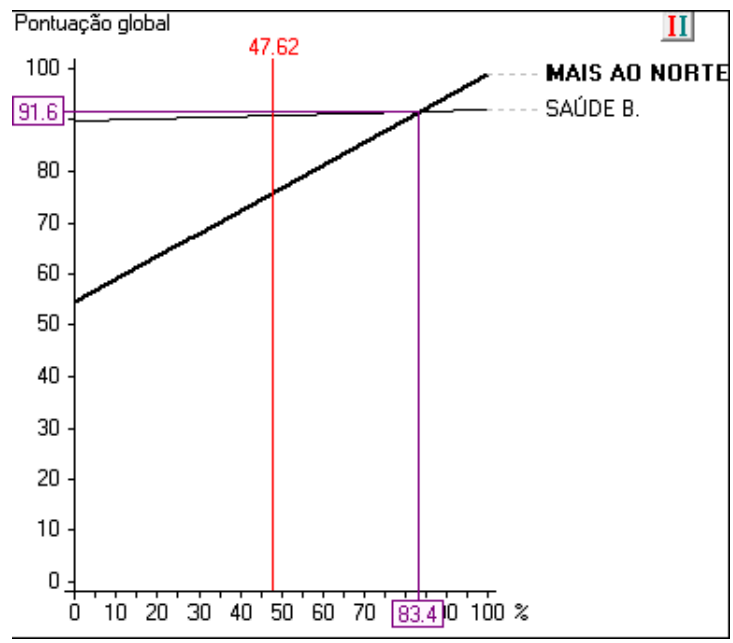

Fonte: Autores (2018).

No critério "Alinhamento estratégico" os projetos mantêm o seu nível de atratividade, como 
pode ser visto na Figura 11, onde as retas não se interceptam. Mesmo sendo apresentada diferença mínima de 4 pontos na tabela de pontuações final do modelo, alterações no resultado da hierarquização de projetos não aconteceriam, visto que este critério apresenta o menor peso, e dessa forma, menor influência no resultado geral.

\section{Figura 11}

Análise e Sensibilidade Do Critério "Alinhamento Estratégico" para os Projetos Saúde Bucal e Mais Ao Norte

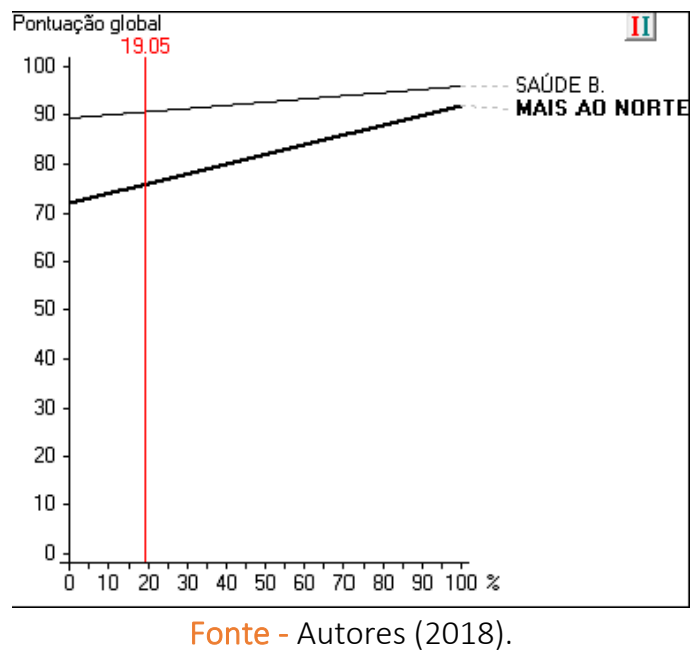

Outra situação é verificada na comparação dos mesmos projetos no critério dependência de terceiros, caso em que se o peso deste nó critério for inferior a 6,8, o projeto Mais ao Norte pode se tornar mais atrativo, assim como verificado na Figura 12.

\section{Figura 12}

Análise de Sensibilidade do Critério "Dependência De Terceiros" Para os Projetos Saúde Bucal e Mais Ao Norte

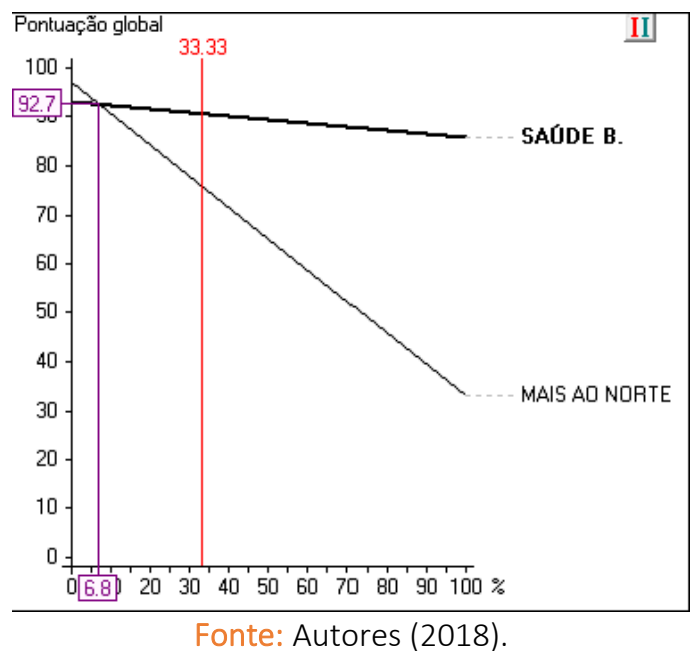

Deve-se observar mesmo ocorrendo a diferença de 53 pontos entre os dois projetos, na análise 
do critério "dependência de terceiros" ocorre diminuição do seu peso drasticamente, desta forma os projetos poderiam ser realocados na escala global final, ocupando posições diferentes.

\section{Considerações finais}

O objetivo de determinar a hierarquia de priorização de projetos de instituição do terceiro setor no município de Marabá utilizando o método MACBETH foi alcançado, logrando êxito ao estudo, como consequência a pesquisa obteve sucesso na sua realização, pois utilizou o método multicritério de decisão MACBETH e realizou hierarquia dos projetos a partir da atratividade de cada um.

Pela metodologia de MACBETH ter seu julgamento de consistência para poder realizar as avaliações entre os critérios e parâmetros (caracterizados nesse estudo como os projetos da instituição), pode-se inferir que os dados utilizados e as informações alcançados são consistentes.

A partir da listagem de projetos com seus respectivos objetivos estratégicos pôde-se notar que há uma grande variação dentre todas as alternativas expostas e cada projeto tem um objetivo estratégico podendo ser direcionado tanto para a organização como um todo, como para uma atividade específica que a entidade realiza.

A configuração da árvore de valores que foi obtida com auxílio da gestora percebe-se que as variáveis dispostas são encontradas em todos os projetos que compõe o portfólio e por isso colaboram para o êxito do estudo. Nota-se com a análise de sensibilidade encontrada tem-se a alteração na hierarquização visível, ou seja, se algum critério tiver seu peso alterado, o projeto ocupando o primeiro nível na escala global pode ser substituído por um que ocupe o terceiro nível, gerando uma nova escala global de hierarquização de opções.

A partir da análise de dados e informações coletadas, foi possível definir quais projetos podem priorizados no gerenciamento de portfólio da instituição, tendo como base o resultado global apresentado não termômetro global gerado a partir da árvore de nó critérios e nós não critérios para cada opção definida no Quadro 1, utilizando o software M-Macbeth.

A dificuldade que rondou a pesquisa foi em interpretar os julgamentos da gestora em relação aos projetos, pois na entrevista foi detectado o seu apego sentimental com alguns dos projetos e isto não pode ser levado em consideração, mesmo o método MACBETH tendo como característica a realização de avaliação qualitativa foi necessário levar em consideração apenas a opinião da administradora da instituição quando baseada em fatos comprovados dos projetos.

Sugere-se para estudos futuros utilização do método Macbeth em outra instituição do terceiro setor para comprovação de seu auxílio neste âmbito social, e a utilização de outro método multicritério, indica-se: AHP, TOPSIS, ELECTREE ou PROMETHEE, usando os mesmos projetos e mesmos parâmetros para comparação com o Macbeth. 
Financiamento

O presente trabalho foi realizado com apoio da Coordenação de Aperfeiçoamento de Pessoal de Nível Superior - Brasil (CAPES) - Código de Financiamento 001.

\section{Referências}

Albuquerque, A. C. (2006). Terceiro Setor: história e gestão de organizações. São Paulo: Summus.

Almeida, A. T. de. (2013). Processo de decisão nas organizações: construindo modelos de decisão multicritério. São Paulo: atlas.

Almeida, N., \& Neto, R. O. (2015). Gestão profissional do Portfólio de projetos: maturidades e indicadores. Rio de janeiro: Brasport.

Andrade, R. O. B., \& Amboni, N. (2010). Estratégias de Gestão: processos e funções do administrador. Rio de Janeiro: Elsevier.

Assumpção, J. J., \& Campos, L. M. de S. (2011). Avaliação de projetos sociais em ONGs da Grande Florianópolis: um estudo sobre modelos relacionados ao foco de atuação. Revista de Administração Pública, 45 (1). https://doi.org/10.1590/\$0034-76122011000100010

Bana e Costa, C., De Corte, J., \& Vansnick, J., (2012). MACBETH. International Journal of of information technology \& decision making, 11 (2), 359-387. https://doi.org/10.1142/S0219622012400068

Bana e Costa, C., De Corte, J., \& Vansnick, J., (2016). On the mathematical foundations of MACBETH. In Greco, S., Matthias, E., Figueira, J. (Eds.), Multiple Criteria Decision Analysis: State of the Art Surveys. (pp. 421-463) New York: Springer.

Carayannis, E. G., Ferreira, F. A. F., Bento, P., Ferreira, J. J. M., Jalali, M. S., \& Fernandes, B. M. Q. (2018). Developing a socio-technical evaluation index for tourist destination competitiveness using cognitive mapping and MCDA. Technological Forecasting \& Social Change, 131, 147-158. https://doi.org/10.1016/j.techfore.2018.01.015

Camargo, M. F. de. (2001). Gestão do terceiro setor no Brasil. São Paulo: Futura.

Duarte, C. de O. S. (2005). Responsabilidade social nas empresas: a contribuição das universidades. São Paulo: Peiropólis: Instituto Ethos.

Franco, J., Pereira, M. F., \& Sartori, R. (2003, dezembro). Captação de recursos para o terceiro setor: um estudo na cidade de Maringá-PR. Anais do Encontro nacional da associação nacional de pós-graduação em administração. Atibaia, São Paulo, Brasil. ANPAD.

Goes, V. P. G. (2017). Aplicação da Matriz de decisão multicritérios e do modelo de facilidades de localização em ambientes competitivos na indústria de pet shops (Dissertação de mestrado). Pontifícia Universidade Católica - PUC, Rio de Janeiro, RJ, Brasil.

Hervieux, C., Gedjlovic, E., \& Turcotte, M. B. (2010). The legitimization of social entrepreneurship. Journal of Enterprising Communities, 4 (1), 37-67. https://doi.org/10.1108/17506201011029500 
Lima, L. F. (2012). Processo Sóciotécnico MACBETH de Apoio Multicritério à Decisão e a Organização de Comunidades Tradicionais: O caso da Comunidade do Marujá no Vale do Ribeira - SP. (Dissertação de mestrado) Universidade Estadual de Campinas, São Paulo, Brasil.

Mccarthy, K. D. (2008). Planejamento circunstancial: economia social terceiro setor. Porto Alegre: EDIPUCRS.

Melo Neto, F. P. de, \& Brennand, J. M. (2004). Empresas socialmente sustentáveis. Rio de Janeiro: Qualitymark.

Nemoto, M. C. O., Silva, D. A., \& Pinochet, L. H. C. (2018). Avaliação de aplicações de boas práticas na gestão de projetos sociais para instituições do terceiro setor. Revista de Gestão e Projetos, 9 (3), 67-80. https://doi.org/10.5585/gep.v9i3.11261

Salamon, L. (1998). A emergência do terceiro setor: uma revolução associativa global. Revista de Administração, 33 (1), 5-11.

Salvatore, V. (2004). Terceiro setor: planejamento \& gestão. São Paulo: Editora Senac.

Segalla, R. R., Zattar, I. C., Lima, A. I., Seleme, R. (2019). Apoio à decisão aplicada à seleção dos requisitos para certificação de incubadoras de base tecnológica no Cerne 2. Revista Exacta, 17 (1), 35-49. https://doi.org/10.5585/exactaep.v17n1.7999

Sousa, J. V., Jerônimo, T. de B., Melo, F. J. C., Aquino, J. T. (2017). Uso do AHP para identificação de perdas da qualidade em empresas de manufatura: um estudo de caso. Revista Exacta, 15 (1), 89-100. https://doi.org/10.5585/exactaep.v15n1.6691

Xavier, C. M. da S., \& Chueri, L. de O. N. (2008). Metodologia de gerenciamento de projetos no terceiro setor: uma estratégia para condução de projetos. Rio de Janeiro: Brasport. 
APÊNDICE

Apêndice A

Matriz de Julgamento do Critério "Complexidade"

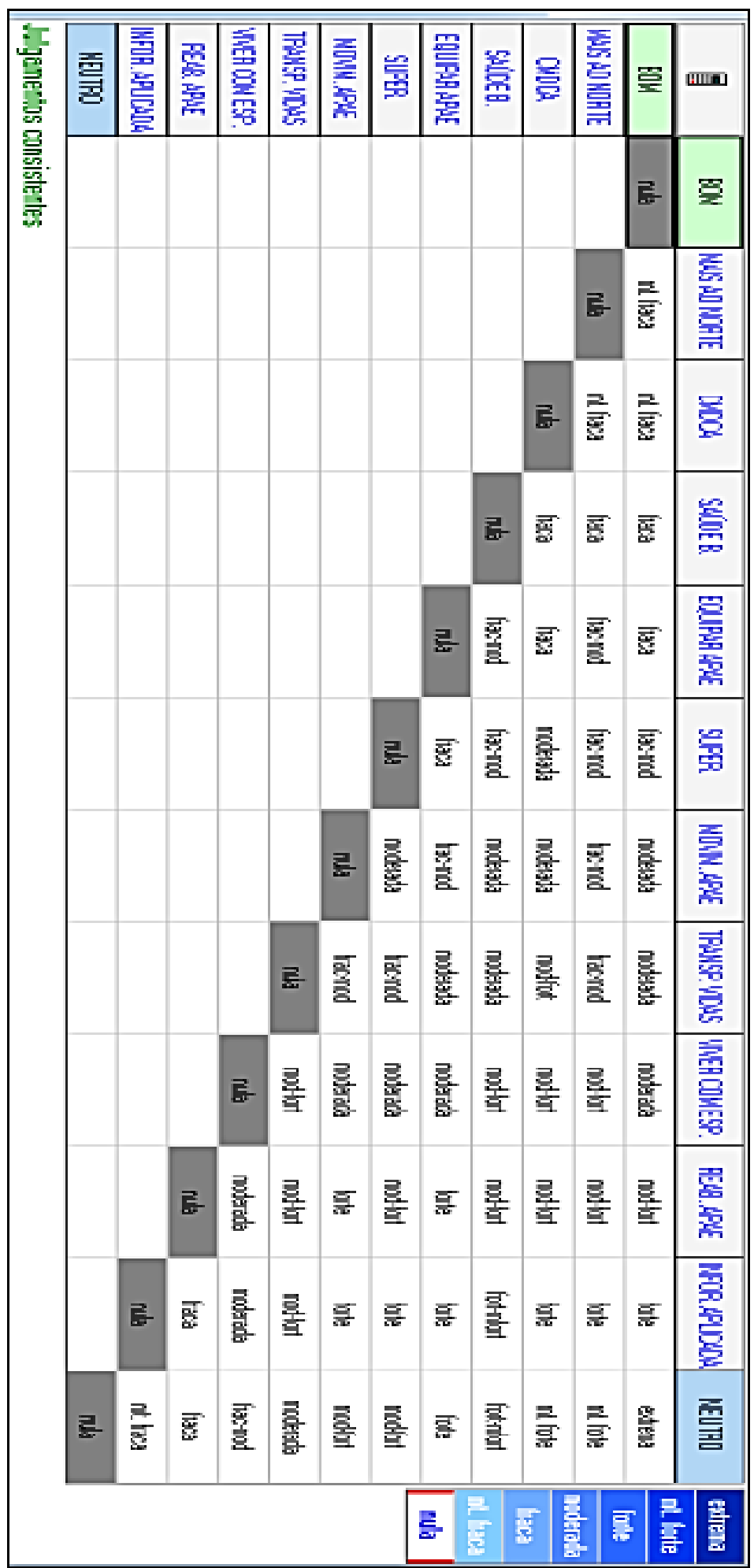

Fonte: Autores (2018). 
Apêndice B

Matriz de Julgamento do Critério "Alinhamento Estratégico"

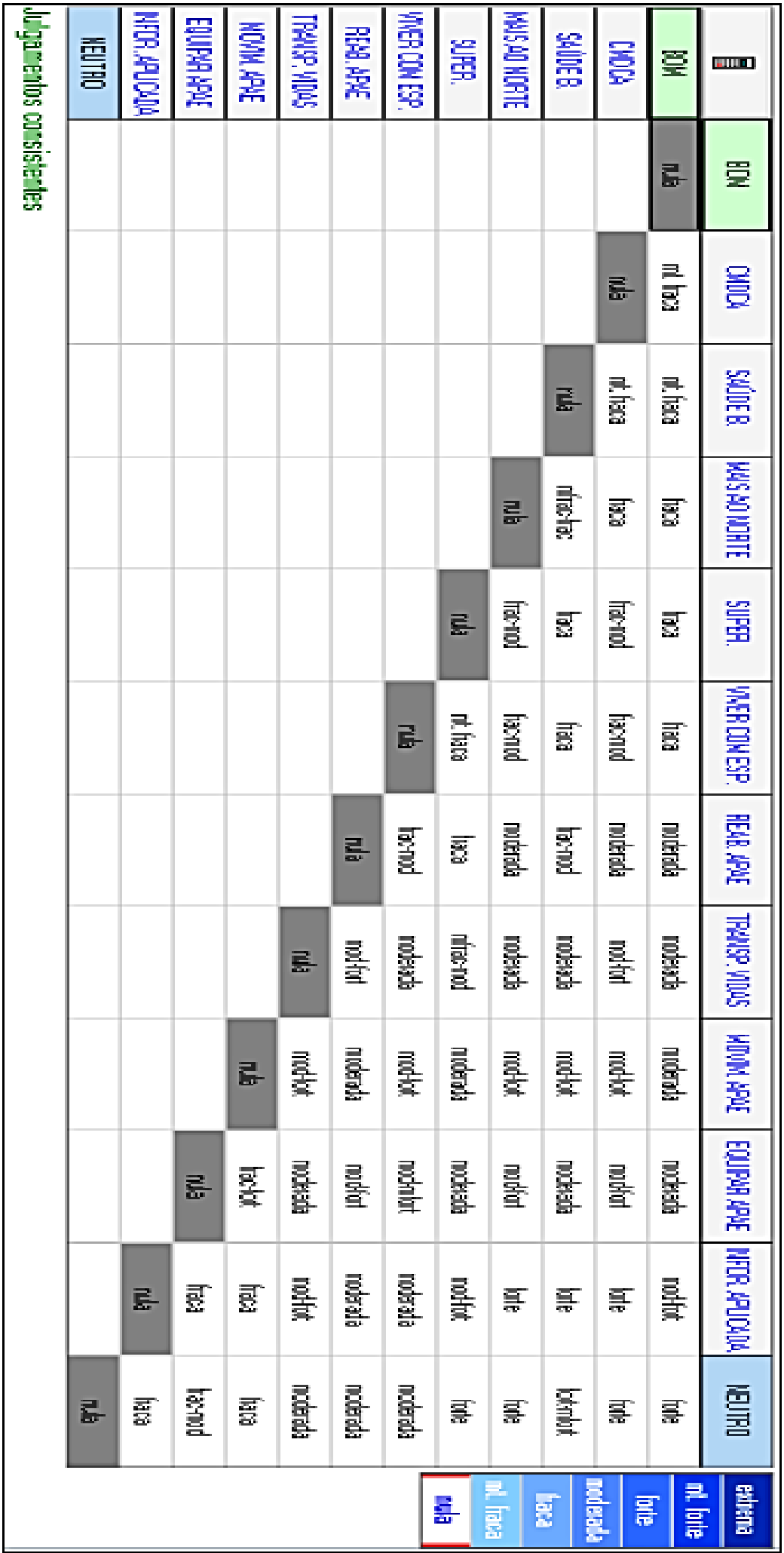

Fonte: Autores (2018). 
Apêndice C

Matriz de Julgamento Do Critério "Dependência De Terceiros"

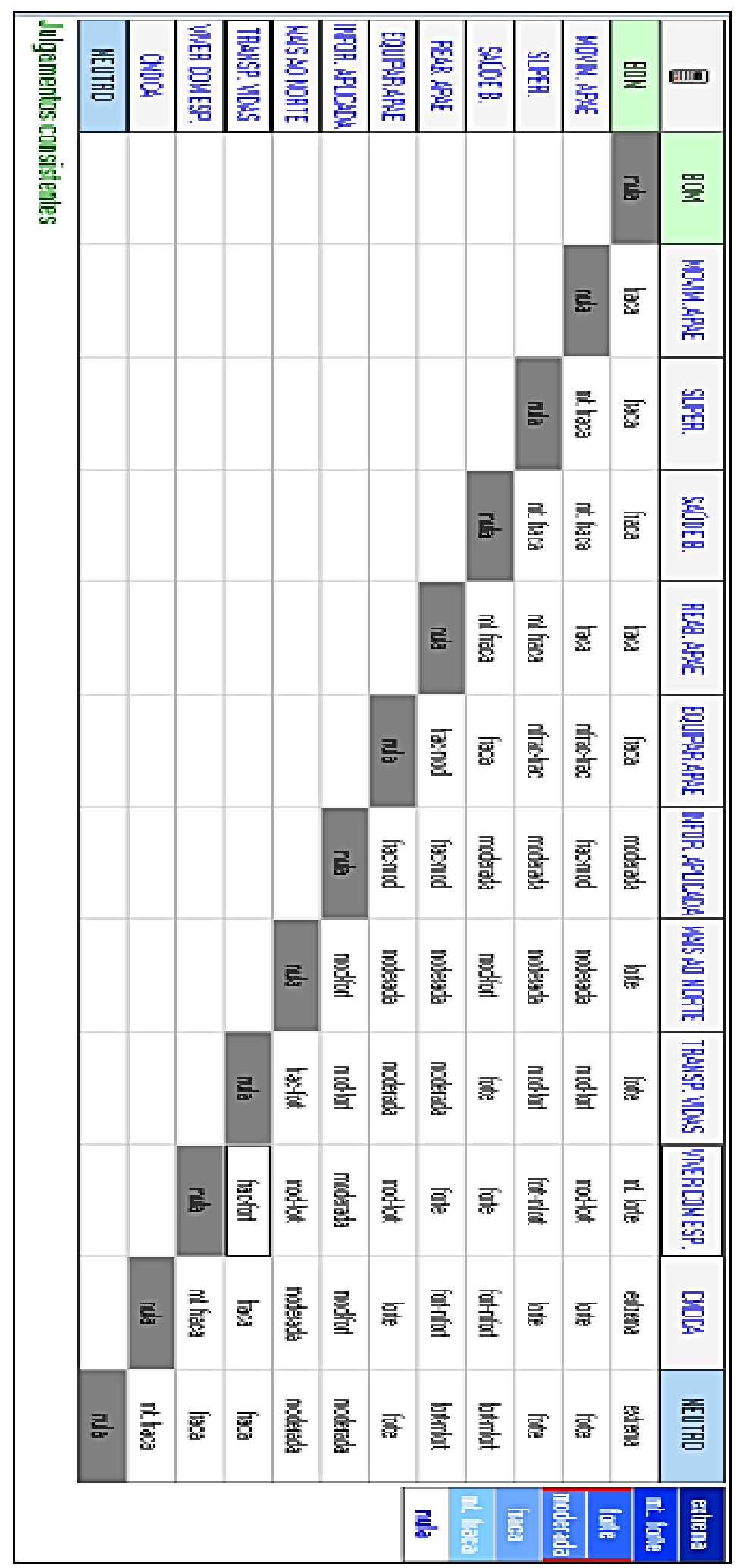

Fonte: Autores (2018). 